\title{
Preparation and Characterization of Directly Compressible Spherical Agglomerates of Etoricoxib
}

\author{
Hagalavadi Nanjappa Shivakumar ${ }^{1}$, Vanita Somasekhar ${ }^{2, \star}$, Anwesha Roy ${ }^{1}$ \\ ${ }^{1}$ Department of Pharmaceutics, KLE College of Pharmacy, II Block Rajajinagar, Bangalore, Karnataka, INDIA. \\ ${ }^{2}$ Department of Pharmaceutical Chemistry, KLE College of Pharmacy, II Block Rajajinagar, Bangalore, Karnataka, INDIA.
}

\begin{abstract}
Aim: The current work contemplates formulation of spherical agglomerates of Etoricoxib, with a view to improve the flow properties, solubility and dissolution rate. Materials and Methods: Spherical agglomerates of etoricoxib were produced employing quasi emulsion solvent diffusion method using hydrophilic polymers like PVP K30 and PEG 6000. IR spectroscopy and Scanning Electron Microscopy along with physicochemical evaluations were used to characterize the agglomerates. Results: The optical microscopic studies indicated that the agglomerates were spherical in shape and varied in size from 1203.9 $\pm 126 \mu \mathrm{m}$ to $1297.2 \pm 164.2 \mu \mathrm{m}$. The technique was found to enhance the aqueous solubility of the drug from $1.45 \mu \mathrm{g} / \mathrm{ml}$ to $8.26 \pm 0.05 \mu \mathrm{g} / \mathrm{ml}$ and the dissolution in 60 min from $39.57 \%$ to $82.88 \%$. Etoricoxib tablets prepared using spherical agglomerates with PVP K30 and PEG 6000 displayed dissolution of $82.88 \%$ and $76.89 \%$ respectively that were considerably higher than conventional etoricoxib tablets. Conclusion: From the dissolution profile and \% cumulative release from formulations it was concluded that Spherical Agglomeration technique substantially improves the flow properties, aqueous solubility and rate of dissolution of etoricoxib.
\end{abstract}

Key words: Etoricoxib, Spherical, Agglomerates, Directly compressible, Flow properties, Rate of dissolution.

\section{INTRODUCTION}

Direct compression is a simple and economical technique for tableting which has fewer steps and suited for drugs prone to be affected by heat or moisture. ${ }^{1}$ However, owing to deficient binding or bonding properties, many drugs are not able to be directly compressed. ${ }^{2}$ Hence, it becomes necessary to include large amounts of directly compressible excipients that invariably increase the production cost. To overcome this limitation, an attractive avenue is modification of physicochemical properties of the drug by different particle engineering strategies. ${ }^{3}$ One such technique gaining popularity is Spherical Agglomeration (SA) that employs comparatively fewer steps in tableting process. SA involves simultaneous crystallization and agglomeration to obtain a compact spherical material that leads to improved flow ability as well as compressibility and thereby proves cost effective. $^{4}$

Spherical crystallization technique necessitates the use of three solvent systems in the form of a dispersion medium, solvent for dissolution of the substance and the wetting or bridging solvent. ${ }^{5}$ The technique produces spherical agglomerates (SAs) that can be employed as intact spheres or directly compressible material with adequate micrometric, compressional and dissolution properties. Spherical agglomeration may be used as a technique for particle size enlargement by adding an immiscible bridging liquid to agglomerate crystals prior to deliquoring. ${ }^{6}$ Addition of bridging liquid to drug solutions results in
Submission Date: 10-05-2020; Revision Date: 07-07-2020; Accepted Date: 25-09-2020

DOI: 10.5530/ijper.54.4.192 Correspondence: Dr. Vanita Somasekhar KLE College of Pharmacy, II Block Rajajinagar, Bengaluru-560010, Karnataka, INDIA.

Phone no: +91-9341221778 Email id: vanitasom@gmail. com

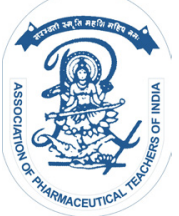

www.ijper.org 
immediate agglomeration. Improved flow ability and compressibility can be achieved by adjusting the amount of bridging liquid and the stirring speed. ${ }^{78}$ The SAs can be used as final dosage form in capsules. It is possible to change the proportion of excipients used in the SA to obtain predictable drug release. The SAs having different drug release properties can be color coded too. It is possible to formulate the SAs of only excipients, which can be used as placebo therapy.

Etoricoxib (ETX) is a NSAID belonging to second generation cyclooxygenase-2 (COX-2) inhibitor that is prescribed as an analgesic and anti-inflammatory drug for arthritic ailments like rheumatoid arthritis. A number of specialized formulations of etoricixib for injectable and transdermal administration have been developed for treatment and management of musculoskeletal disorders. Bio-adhesive hybridized polylactic acid-based nanoparticles of the drug have been proposed for intraarterial administration in the treatment of osteoarthritis. Poly (caprolactone) micro particles loaded composite chitosan gel has been developed for intrarticular depot delivery for treatment of osteoarthritic condition. ${ }^{10} \mathrm{An}$ ethosomal formulation of the drug is proposed for management of skin inflammation. ${ }^{11}$ However, peroral route continues to be the most preferred mode of administration for etoricoxib. But, the major problem associated with the drug is its poor aqueous solubility resulting in low dissolution rate. The drug is also known to possess poor micrometric property as well. Considering these drawbacks, the present study aimed to produce SAs of etoricoxib to enhance solubility, micrometrics and rate of dissolution.

\section{MATERIALS AND METHODS}

Etoricoxib was a gift sample from Indian Fine Chemicals Private Limited, Mumbai, India. PVP K30 polymer was procured from Colorcon Private Limited, Verna, Goa, India. All other chemicals and solvents of analytical grade were procured from Sd Fine Chemicals, Mumbai, India.

\section{Preformulation and solubility studies}

Flow properties of etoricoxib was determined by measuring the angle of repose by fixed funnel method. Properties like Bulk density, Tapped density, Hausner's ratio, Carr's index were also measured. ${ }^{12}$

Solubility studies of etoricoxib were done according to method described by Higuchi and Connors. An excess quantity of drug was taken in vials containing $10 \mathrm{ml}$ of media. The vials were shaken in water bath (100 strokes per min) for $24 \mathrm{hr}$ at room temperature.
The solutions were then filtered using Whatman filter paper and the solubility of the drugs were analyzed spectrophotometric ally after suitable dilutions. The solubility of the drug was determined in distilled water, pH 1.2 buffer solution.

\section{Drug-Excipients interaction Infrared (FTIR) spectroscopy}

FTIR scanning was employed to detect presence of any chemical interaction of the drug with formulation excipients. The powdered sample and dry powdered potassium bromide were mixed thoroughly. The resulting mixture was loaded in a diffuse reflectance sampler and scanned over the wavelength range of $4000-400 \mathrm{~cm}^{-1}$ in an FTIR spectrophotometer (Jasco 460 plus, Japan). The IR spectrum of the physical mixture and SAs were compared with the spectra of ETX to detect any possible interaction between ETX and excipients used.

\section{Preparation of agglomerates by Quasi Emulsion Solvent Diffusion (QESD) Method}

A solution of ETX $(1 \mathrm{~g})$ was prepared in ethanol $(5 \mathrm{ml})$ used as a good solvent. About $1 \mathrm{ml}$ of chloroform was added as a bridging solvent to the solution of drug in ethanol to obtain a clear solution, which was then added drop wise into aqueous solution $(75 \mathrm{ml})$ of polymer. ${ }^{13}$ The type and amount of polymer in the aqueous phase was varied as indicated in Table 1 . The mixture produced was stirred at $1000 \mathrm{rpm}$ at constant rate for 30 min. The resulting SAs were then recovered by filtration and subjected to drying at room temperature.

\section{Characterization and evaluation of agglomerates Scanning Electron Microscopy (SEM)}

SEM was employed to examine the surface topography and morphology of prepared SAs. ${ }^{14}$ To enhance the conductivity, an ion sputtering device (JEOL, JFC-1100 $\mathrm{E}$, Japan) was used for $5 \mathrm{~min}$ under reduced pressure ( 0.001 torr) to coat gold $\left(200^{\circ} \mathrm{A}\right)$ on the samples, which were then subjected to SEM (JEOL, JSM-840A, Japan).

\section{Estimation of drug content}

Powdered SAs containing $50 \mathrm{mg}$ ETX was weighed and solubilized in buffer ( $\mathrm{pH}$ 1.2). Subsequently, the solutions were filtered $(0.45 \mu \mathrm{m}$, Millipore) and suitably diluted to

Table 1: Formulation composition of various batches
of agglomerates.
\begin{tabular}{|c|c|c|c|c|c|c|}
\hline Agglomerate Ingredients & SA1 & SA2 & SA3 & SA4 & SA5 & SA6 \\
\hline Etoricoxib (g) & 1 & 1 & 1 & 1 & 1 & 1 \\
\hline PVP K30 (g) & 1 & 2 & 3 & - & - & - \\
\hline PEG 6000 (g) & - & - & - & 1 & 2 & 3 \\
\hline
\end{tabular}


determine the drug content with UV spectrophotometer at $233 \mathrm{~nm}$ (Jasco UV spectrophotometer) using buffer (pH 1.2) as blank. From the absorbance, drug content of the SAs was calculated using equation 1.

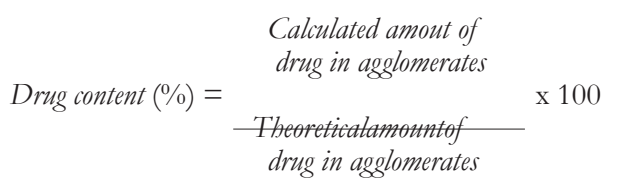

\section{Determination of Micromeritic Properties}

Determination of Tapped Density was undertaken by transferring SAs (20g) into a $50 \mathrm{ml}$ measuring cylinder. Using a bulk density apparatus (M/s Cambell Electronics, India), the cylinder was tapped to a constant volume at 100 strokes $/ \mathrm{min} .{ }^{12}$ Likewise, bulk density was found out by loading same amount of granules into the measuring cylinder and tapping it three times in the same apparatus at the same speed. The final volumes were noted down in each case and using equations 2 and 3 , the tapped density and bulk density were calculated respectively. The Carr Compressibility Index and Hausner ratio of SAs was computed from the values of the tapped density and bulk density using equations 4 and 5 respectively.

$$
\begin{aligned}
& \text { Tapped density }=\frac{\operatorname{mass}(\mathrm{g})}{\operatorname{tapped} \text { volume }(\mathrm{ml})} \\
& \text { Bulk density }=\frac{\operatorname{mass}(\mathrm{g})}{\text { Bulk volume }(\mathrm{ml})}
\end{aligned}
$$

$\begin{aligned} & \text { Compressibility } \\ & \text { Index }(\%)\end{aligned}=\frac{\begin{array}{l}\text { Tapped } \\ \text { density }\end{array}-\begin{array}{c}\text { Bulk } \\ \text { density }(\mathrm{g})\end{array}}{\text { Tapped density }} \times 100$

$$
\text { Hausner's ratio }=\frac{\text { Tapped density }}{\text { Bulk density }}
$$

\section{Determination of angle of repose}

Fixed funnel method was adopted, wherein at a constant height of $2.5 \mathrm{~cm}$ above a horizontal surface, a funnel was secured through which the SAs were carefully allowed to pass until the tipof the cone-shaped assemblage just came in contact with the lower funnel tip. ${ }^{12}$ Measuring the height and diameter of the assemblage enabled the calculation ofthe angle of repose using equation 6 .

$$
\theta=\tan ^{-1} \frac{\mathrm{H}}{\mathrm{r}}
$$

Where $r$ and $H$ represent the radius and height of the cone-shaped assemblage.

\section{Determination of mean particle size}

Optical microscopy was employed to determine the particle size of the prepared SAs. ${ }^{15}$ The mean projected diameter of 400 SAs from each batch was measured with an eye piece micrometer that was calibrated with a stage micrometer at suitable magnification before the measurement of particle size.

\section{Solubility Studies}

Solubility studies of ETXand SAs were conducted as per method described by Higuchi and Connors. Drug in excess was taken in vials having $10 \mathrm{ml}$ of distilled water. The vials shook on a water bath (100 strokes per min) at room temperature for a period of $24 \mathrm{hr}$. The resulting dispersions were subsequently filtered using Whatmann filter paper and the solubility of the drugs was analyzed spectrophotometrically after suitable dilutions. ${ }^{16,17}$

\section{Preparation of the tablets by direct compression}

The SAs were made to pass through a sieve to crush the lumps and $1 \% \mathrm{w} / \mathrm{w}$ each of talc and magnesium stearate was added for lubrication (Table 2). The resultant SAs were subjected to compressioninto tablets using an $8.5 \mathrm{~mm}$ flat punch in a rotary 10 station compression machine. (RIMEK MINIPRESS) using a 'B' tooling to a hardness of about $5-6 \mathrm{~kg} / \mathrm{cm}^{2}$.

\begin{tabular}{|c|c|c|c|c|c|c|}
\hline \multicolumn{7}{|c|}{ Table 2: Composition of tablet formulations. } \\
\hline Formulation & F1 & F2 & F3 & F4 & F5 & F6 \\
\hline Agglomerates* & $120 \mathrm{mg}$ & $180 \mathrm{mg}$ & $240 \mathrm{mg}$ & $120 \mathrm{mg}$ & $180 \mathrm{mg}$ & $240 \mathrm{mg}$ \\
\hline Talc & $1 \%$ & $1 \%$ & $1 \%$ & $1 \%$ & $1 \%$ & $1 \%$ \\
\hline $\begin{array}{c}\text { Magnesium } \\
\text { Stearate }\end{array}$ & $1 \%$ & $1 \%$ & $1 \%$ & $1 \%$ & $1 \%$ & $1 \%$ \\
\hline
\end{tabular}

*The Tablets $\mathrm{F}_{1}, \mathrm{~F}_{2}, \mathrm{~F}_{3}, \mathrm{~F}_{4}, \mathrm{~F}_{5}$ and $\mathrm{F} 6$ contained agglomerates $\mathrm{SA}_{1}, \mathrm{SA}_{2}, \mathrm{SA}_{3}, \mathrm{SA}_{4}, \mathrm{SA}_{5}$ and $\mathrm{SA} 6$ respectively. 


\section{Evaluation of tablets \\ Thickness}

The thickness of each of ten tablets randomly selected was measured by digital Vernier caliper. Digital caliper (Mitutoyo Corporation, Kawasaki, Japan) was used to record the values in $\mathrm{mm}$. The mean and standard deviation of the thickness were calculated. ${ }^{18}$

\section{Hardness}

In order to determine the hardness using a Stokes Monsato hardness tester (M/s Cambell Electronics, India), from each batch of tablets, ten tablets were randomly selected. The hardness of each tablet was measured and expressed as $\mathrm{kg} / \mathrm{cm}^{2}$. The arithmetical mean and standard deviation were computed. ${ }^{18}$

\section{Friability}

A USP friabilator was used to determine the friability of tablets of each batch. About twentyweighed tablets from each batch were placed inside the friabilator that was operated for 4 min at $25 \mathrm{rpm} .{ }^{18}$ Then the weight of the tablets was again determined. Equation 7 was used to calculate the friability.

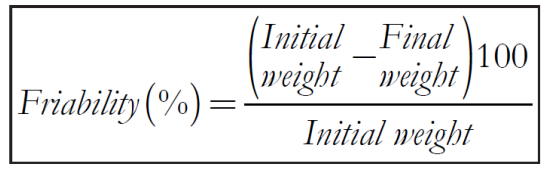

\section{Weight variation test}

The weight variation was determined as per the procedure prescribed in Indian pharmacopeia (IP). From each batch, 20 tablets selected randomly were individually weighed to compute the average weight and its standard deviation. If the deviation of the weights of 2 or less than two individual tablets from the average weight exceeds the permissible limit and none deviate by more than twice the limit then the batch is assumed to have passed the test. The maximum permissible limit is $7.5 \%$ for tablets weighing between 130 to $324 \mathrm{mg} .{ }^{18}$

\section{In vitro disintegration time}

As specified in IP, disintegration test apparatus was used to determine the disintegration time of all formulations. Six tablets were separately placed in each tube of disintegration test apparatus and the discs positioned. The temperature of water was controlled at $37 \pm 2^{\circ} \mathrm{C}$ and the time taken for the tablet to disintegrate completely was recorded. ${ }^{19}$

\section{In vitro dissolution study}

Each batch of tablets was subjected to dissolution study in a USP paddle apparatus. About $900 \mathrm{ml}$ of
$\mathrm{HCl}$ (pH1.2) used as the media was maintained at $37 \pm 0.5^{\circ} \mathrm{C}$ and a paddle stirring speed of $50 \mathrm{rpm}$. Samplesmeasuring $5 \mathrm{ml}$ was withdrawn at a 10,20 , $30,40,50$ and $60 \mathrm{~min}$. and replaced every time with $5 \mathrm{ml}$ of the fresh buffer maintained at $37 \pm 0.5^{\circ} \mathrm{C}$. A spectrophotometer at $233 \mathrm{~nm}$ wavelength was used to measure the absorbance of the withdrawn samples to determine the drug release. ${ }^{20}$ The cumulative drug released was plotted on $\mathrm{Y}$ axis versus time on $\mathrm{X}$ axis to obtain the dissolution profiles.

\section{Statistical Analysis}

The raw data generated were statistically compared by performing ANOVA in GraphPad 5.0 Instat demo version software (GraphPad Inc. CA, USA). The probability value of less than 0.05 was considered to be significant.

\section{RESULTS AND DISCUSSION \\ Preformulation and solubility studies}

When subjected to preformulation studies, ETX displayed a Hausner's ratio of 1.50 and Carr's index of $33.6 \%$ with an angle of repose of $30^{\circ}$. From these values it can be inferred that the drug has very poor flow properties. Poor flow properties can pose a problem in direct compression. ${ }^{12}$ Solubility studies of ETX revealed an aqueous solubility of $1.45 \pm 0.07 \mu \mathrm{g} / \mathrm{ml}$, whereas solubility in $\mathrm{pH} 1.2 \mathrm{HCl}$ buffer was $18.5 \pm 0.11 \mu \mathrm{g} / \mathrm{ml}$. This indicated that the drug has low solubility in water but is more easily soluble in $\mathrm{pH} 1.2 \mathrm{HCl}$ buffer.

\section{Infrared (FTIR) spectroscopy}

The FTIR spectrum study revealed three prominent peaks at $2862.81 \mathrm{~cm}^{-1}, 3462.56 \mathrm{~cm}^{-1}$ and $1429.96 \mathrm{~cm}^{-1}$ which may be assigned to $\mathrm{C}-\mathrm{H}$ stretch present in aliphatic group (Alkane), N-H group and $\mathrm{C}-\mathrm{C}$ stretch respectively.

These prominent peaks of the ETX were also apparent in spectrum of the physical mixture at 2860.51 $\mathrm{cm}^{-1}, 3460.26 \mathrm{~cm}^{-1}$ and $1425.76 \mathrm{~cm}^{-1}$. Likewise, the characteristic peaks of ETX were observed at 2858.21 $\mathrm{cm}^{-1}, 3450.12 \mathrm{~cm}^{-1}$ and $1424.46 \mathrm{~cm}^{-1}$ in the spectra of the formulations. The appearance of drug characteristic peaks in the spectra of physical mixture as well as formulation indicates ETX had maintained its chemical integrity in the physical mixture and in the formulation. The studies thus rule out possibility of any drug-excipient interactions and therefore the potential incompatibility of the drug with other excipients used. IR has been used as a useful tool to study the possible incompatibility issues between drug and various excipients. ${ }^{13}$ 


\section{Preparation of agglomerates by Quasi Emulsion Solvent Diffusion (QESD) Method}

In the preparation of SAs of ETX, it was noted that the solvent system greatly influences the process of formation of SAs and their properties. Hence an important step in the formation of SAs was the selection of suitable solvent system. In the initial trials chloroform, dichloromethane, methanol, acetone-ethanol was used to prepare SAs, which performed the dual role of good solvent and bridging liquid. However, the SAs formed were irregularly shaped and some formulations appeared as opaque solutions. Hence in further trials, the above solvents were replaced with ethanol which proved a good solvent and chloroform which played the role of bridging liquid. With this solvent system, the SAs formed were discrete, free flowing and spherical with good micrometric properties.

After selecting a suitable solvent system, the next step was to optimize the process parameters. The SAs were prepared using different processing temperatures ranging from $5^{\circ} \mathrm{C}$ to $25^{\circ} \mathrm{C}$. At $5^{\circ} \mathrm{C}$, sticky fragments were formed. On the other hand, very few SAs with irregular shape and size were formed when the preparation was executed at $15^{\circ} \mathrm{C}$. At room temperature $\left(25 \pm 5^{\circ} \mathrm{C}\right) \mathrm{SAs}$ were formed with good yield, shape and size. Effect of agitation speed on the properties of SAs was also studied. The SAs were prepared at different rpms and stirring time to study the effect of agitation on their properties. At lower rpm $(<800)$ the SAs formed were not homogenous in size and irregular in shape while at higher $\mathrm{rpm}(>1200 \mathrm{rpm}$ ), the SAs formed were very fine in size drastically hampering the flow properties. However, at $1000 \mathrm{rpm}$, the SAs formed were free flowing with good sphericity and flow properties. The time of stirring was also found to be critical in preparation of SAs. At stirring time of $5 \mathrm{~min}$ SAs were not formed whereas at $15 \mathrm{~min}$, the SAs were partially formed. On the other hand, when the stirring was carried out for $30 \mathrm{~min}$, the SAs were found to be completely formed. Based on these observations, a temperature of $25 \pm 5^{\circ} \mathrm{C}$ and stirring for $30 \mathrm{~min}$ at $1000 \mathrm{rpm}$ was considered to be ideal for formation of SAs of ETX. Among the various hydrophilic polymers investigated, PVP K30 and PEG6000 were found most suitable to prepare SAs of ETX. PVP K30 was used in formulations F1 to F3 and PEG6000 in formulations F4 to F6 in varying concentrations.

\section{Characterization and Evaluation of agglomerates Scanning Electron Microscopy (SEM)}

Scanning electron microscopic studies revealed that the SAs appeared to be discrete and near-spherical in shape.
The optical microscopic studies indicated that the SAs of different batches were spherical in shape and varied in size from $1203.9 \pm 126 \mu \mathrm{m}$ to $1297.2 \pm 164.2 \mu \mathrm{m}$ (Figure 1).

\section{Determination of micromeritic properties}

SAs of ETX prepared with PVP K30 and PEG 6000 were found to significantly improve $(P<0.05)$ the flow properties. The angle of repose values of the SAs ranged from 21.1 to $22.7^{\circ}$ while the Carr's index varied from 11.86 to $13.63 \%$ indicating a considerable enhancement in the flow properties. Likewise, the Hausner's ratio varied from 1.13 to 1.15 suggesting the 'good' flow properties of the SAs produced (Table 3). A Carr's index of $11-15 \%$, Hausner's ratio of 1.12-1.18 and angle of repose values of $20-30^{\circ}$ suggests good flow properties. ${ }^{15}$

\section{Solubility studies}

ETX was found to exhibit poor aqueous solubility of $1.45 \mu \mathrm{g} / \mathrm{ml}$ on equilibrating with water for $24 \mathrm{~h}$. However, the technique of SA was found to significantly increase $(P<0.05)$ the solubility of ETX. The solubility

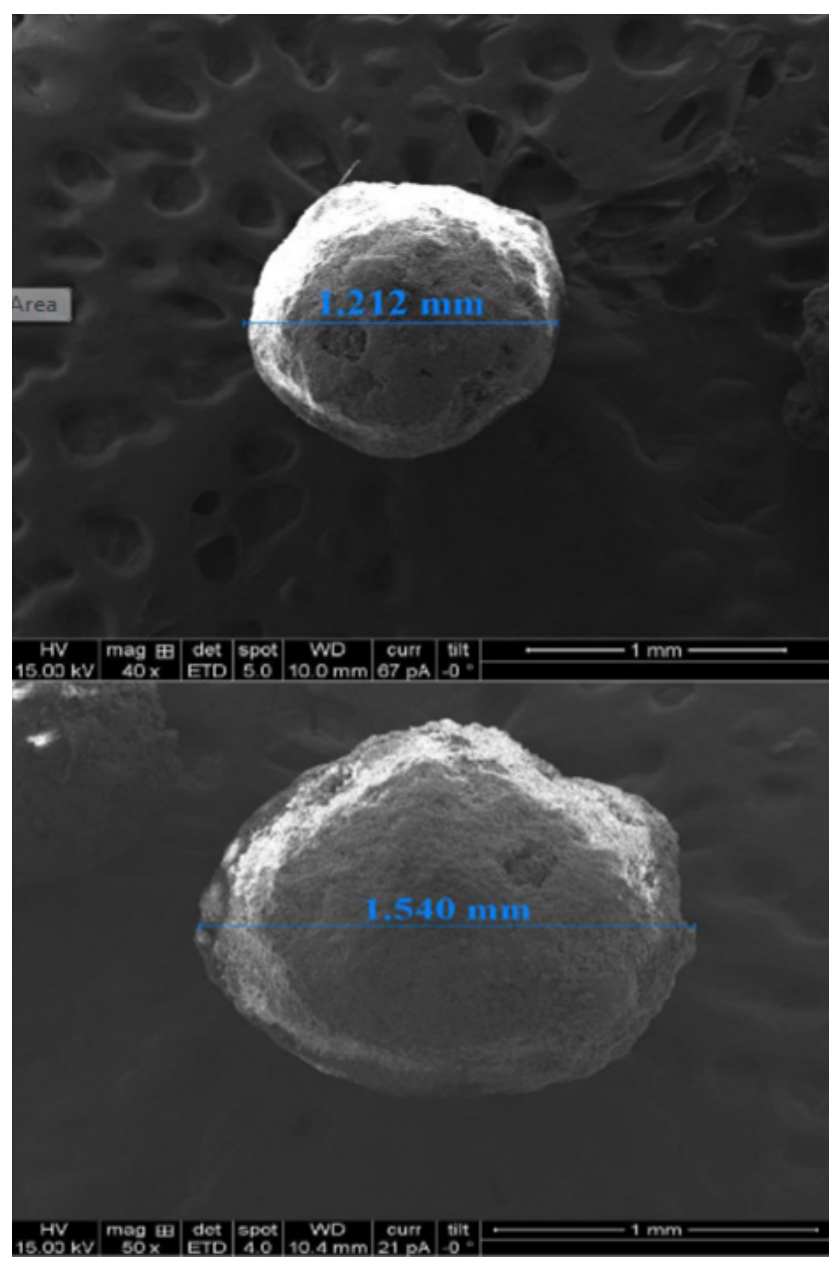

Figure 1: SEM of Spherical agglomerates of Etoricoxib. 


\begin{tabular}{|c|c|c|c|c|c|c|}
\hline \multicolumn{7}{|c|}{ Table 3: Micromeritic properties of etoricoxib and its spherical agglomerates. } \\
\hline Formulations & $\begin{array}{c}\text { Bulk density* (gm/ } \\
\mathbf{m l})\end{array}$ & $\begin{array}{c}\text { Tapped density* } \\
(\mathbf{g m} / \mathbf{m l})\end{array}$ & $\begin{array}{c}\text { Carr's } \\
\text { index (\%) }\end{array}$ & Hausner's ratio & $\begin{array}{c}\text { Angle of } \\
\text { Repose }\end{array}$ & $\begin{array}{c}\text { Solubility in water* } \\
(\boldsymbol{\mu g} / \mathrm{ml})\end{array}$ \\
\hline Etoricoxib & $0.83 \pm 0.02$ & $1.25 \pm 0.06$ & 33.6 & 1.50 & $30^{\circ}$ & $1.45 \pm 0.07$ \\
\hline F1 & $0.44 \pm 0.04$ & $0.50 \pm 0.07$ & 13.63 & 1.13 & $21.5^{\circ}$ & $3.73 \pm 0.10$ \\
\hline F2 & $0.58 \pm 0.03$ & $0.67 \pm 0.01$ & 12.51 & 1.14 & $22.1^{\circ}$ & $6.49 \pm 0.03$ \\
\hline F3 & $0.60 \pm 0.04$ & $0.69 \pm 0.03$ & 13.04 & 1.15 & $22.7^{\circ}$ & $8.26 \pm 0.05$ \\
\hline F4 & $0.41 \pm 0.10$ & $0.47 \pm 0.06$ & 12.76 & 1.14 & $21.1^{\circ}$ & $2.60 \pm 0.06$ \\
\hline F5 & $0.48 \pm 0.02$ & $0.55 \pm 0.01$ & 12.72 & 1.14 & $21.8^{\circ}$ & $4.83 \pm 0.07$ \\
\hline F6 & $0.52 \pm 0.06$ & $0.59 \pm 0.05$ & 11.86 & 1.13 & $22.4^{\circ}$ & $7.39 \pm 0.11$ \\
\hline
\end{tabular}

* The values represent mean $\pm S D$

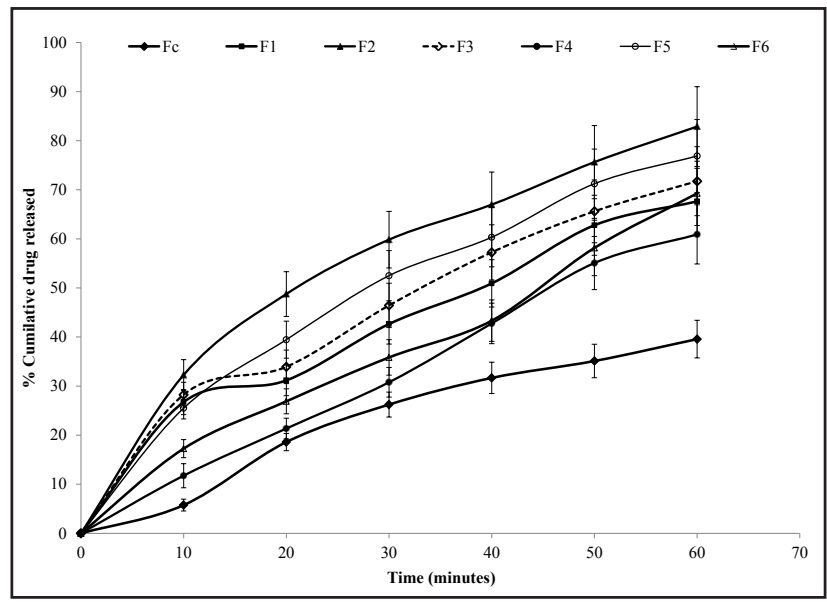

Figure 2: Dissolution profile of Etoricoxib tablets containing agglomerates prepared using PVPK30 and PEG6000.

of SAs were found to be $3.73 \pm 0.10,6.49 \pm 0.03$, $8.26 \pm 0.05,2.60 \pm 0.06,7.39 \pm 0.11,4.83 \pm 0.07 \mu \mathrm{g} / \mathrm{ml}$ for SAs of batches F1, F2, F3, F4, F5 and F6 respectively. The increase in solubility of SAs can be ascribed to the hydrophilicity of the polymers. The enhancement of solubility in presence of PVP K30 can be attributed to its anti-nucleating property.

Further increase in the proportion of polymers failed to further increase the solubility of ETX.

\section{Preparation and evaluation of tablets}

SAs were further compressed into tablets after blending with talc $(1 \% \mathrm{w} / \mathrm{w})$ as a lubricant and magnesium stearate $(1 \%)$ as a glidant. The resulting tablets were subjected to evaluation of tablet properties including hardness, thickness, weight variation, friability, disintegration time and in vitro dissolution of drug. The batches of tablets produced were found to conform to the Indian Pharmacopoeial specifications. The percentage cumulative release of drug from formulations F1, F2, F3, F4, F5 and F6 at 60 min was found to be $67.64 \%, 82.88 \%, 71.75 \%, 60.90 \%, 76.89 \%$ and $69.27 \%$ respectively (Figure 2). Formulation F2 was found to exhibit the highest cumulative release and therefore considered the ideal formulation. The likely reason for the better performance of the formulation can be attributed to the dispersing and anti-nucleating property of PVPK30. The other formulation that gave a comparable dissolution was F5 that was produced with PEG6000. The dissolution data obtained was found to correlate well with the solubility data. The batches of SAs that exhibited better solubility were found to display better dissolution when compressed into tablets.

\section{CONCLUSION}

From the current investigations, it can be concluded that directly compressible SAs of ETX can be successfully produced by SA technique. The agglomerates drastically augmented flow properties of the drug and displayed better solubility that consequently enhanced the dissolution rate of the drug. Hence, agglomerates produced were able to be directly compressed on account of their enhanced flow properties and better compaction behavior. Therefore, SA can be a useful tool in formulation development of poorly compressible drugs. The SAs can finally be dispensed as capsules or compressed tablets as per the need.

\section{ACKNOWLEDGEMENT}

The authors are grateful and wish to thank the Principal, KLE College of Pharmacy, Bengaluru for providing the necessary facilities to carry out this work.

\section{CONFLICT OF INTEREST}

The authors declare no conflict of interest.

\section{ABBREVIATIONS}

PVP K30: Polyvinylpyrrolidone K30; PEG 6000: Polyethylene Glycol 6000; SA: Spherical agglomeration; 
SAs: Spherical agglomerates; ETX: Etoricoxib; NSAID: Nonsteroidal anti-inflammatory drugs; QESD: Quasi Emulsion Solvent Diffusion; SEM: Scanning Electron Microscopy; FTIR: Fourier Transform Infra-Red; USP: United States Pharmacopoeia; IP: Indian Pharmacopoeia.

\section{REFERENCES}

1. Yadav AV, Yadav VB. Designing of pharmaceuticals to improve physicochemical properties by spherical crystallization techniques. $\mathrm{J}$ of Pharm Res. 2008;1(2):105-12.

2. Chourasia MK, Jain NK, Jain S, Jain NK, Jain SK. Preparation and characterization of agglomerates of flurbiprofen by spherical crystallization technique. Indian J Pharm Sci. 2003;65(3):287-91.

3. Paradkar AR, Pawar AP, Jadhav NR. A novel particle engineering technique. Asian J Pharm. 2010;4:4-10.

4. Mahanty S, Sruti J, Niranjan PC, Bhanoji RME. Particle Design of drugs by Spherical Crystallization Techniques. Int J Pharm Sciences and Nanotechnology. 2010;3(2):912-4.

5. Kallies B, Konig A, Ulrich J. Solidification by crystallization in dropsm international workshop for industrial crystallization. Breman, Germany. 1993:138.

6. Kate P, Pe na R, Jonathan DT, Kanjakha P, Rachel S, Zoltan K. et al. Litster. Particle design via spherical agglomeration: A critical review of controlling parameters, rate processes and modelling. Powder Technology. 2018;326:327-43.

7. Wu S, Li K, Zhang T, Gong J. Size control of Atorvastatin Calcium particles based onSpherical Agglomeration. Chem Eng Technol. 2015;38(6):1081-7.
8. Maghsoodi M. Effect of process variables on physicomechanical properties of the agglomerates obtained by spherical crystallization technique. Pharm Dev Technol. 2011;16(5):474-82.

9. Alaa HS, Abdelfattah AA, Nermeen AE. Etoricoxib-loaded bio-adhesive hybridized polylactic acid-based nanoparticles as an intra-articular injection for the treatment of osteoarthritis. Int J Pharm. 2020;578:119081.

10. Arunkumar P, Indulekha S, Vijayalakshmi S, Srivastava R. Synthesis, characterizations, in vitro and in vivo evaluation of Etoricoxib-loaded Poly (Caprolactone) microparticles--a potential Intra-articular drug delivery system for the treatment of Osteoarthritis. J Biomater Sci Polym Ed. 2016;27(4):303-16.

11. Suruchi R, Brijesh SK. Transdermal delivery of Etoricoxib through ethosomal formulation: An ingenious approach towards treatment of skin inflammation. Journal of Drug Delivery Science and Technology. 2017;40:95-104.

12. Aulton ME. Pharmaceutics: The Science of Dosage form Design. $2^{\text {nd }}$ ed. NewYork: Churchill Livingstone. 2002.

13. Patil SV, Sahoo SK. Spherical crystallization: A method to improve tabletability. Research J of Pharmacy and Technology. 2009;2(2):234-7.

14. Kangale P, Lohray BB, Mishra A, Davada P, Kini R. Formulation and optimization of porous osmotic pump based controlled release system of Oxybutinin. AAPS Pharm Sci Tech. 2007;8(3):E1-7.

15. Patel JK, Bodar MS, Amin AF, Patel MM. Formulation and optimization of mucoadhesive microsphere of Metaclopramide. Ind J Pharm Sci. 2004;66(3);300-5.

16. Das A, Nayak AK, Mohanty B, Panda S. Solubility and dissolution enhancement of etoricoxib by solid dispersion technique using sugar carriers. Research Article. 2011. http://www.ncbi.nlm.nih.gov/pmc/articles/ PMC 3263729/

17. http://www.scholarsresearch library.com

18. Lachman L, Lieberman HA, Kanig JL. The Theory and Practice of Industrial Pharmacy. $2^{\text {nd }}$ ed. Bombay: Varghese Publishing House. 1976;69.

19. Khan KA, Sarfaraz MD, Doddayya H. Design and evaluation of Aceclofenac fast dissolving tablets prepared by crystallo-co-agglomeration technique. Int J Pharm Pharm Sci. 2011;3(4):116-23.

20. Lieberman HA, Lachman L. Pharmaceutical dosage forms: Tablets. $2^{\text {nd }}$ ed. New York: Marcel Dekker. 1990;299-333.

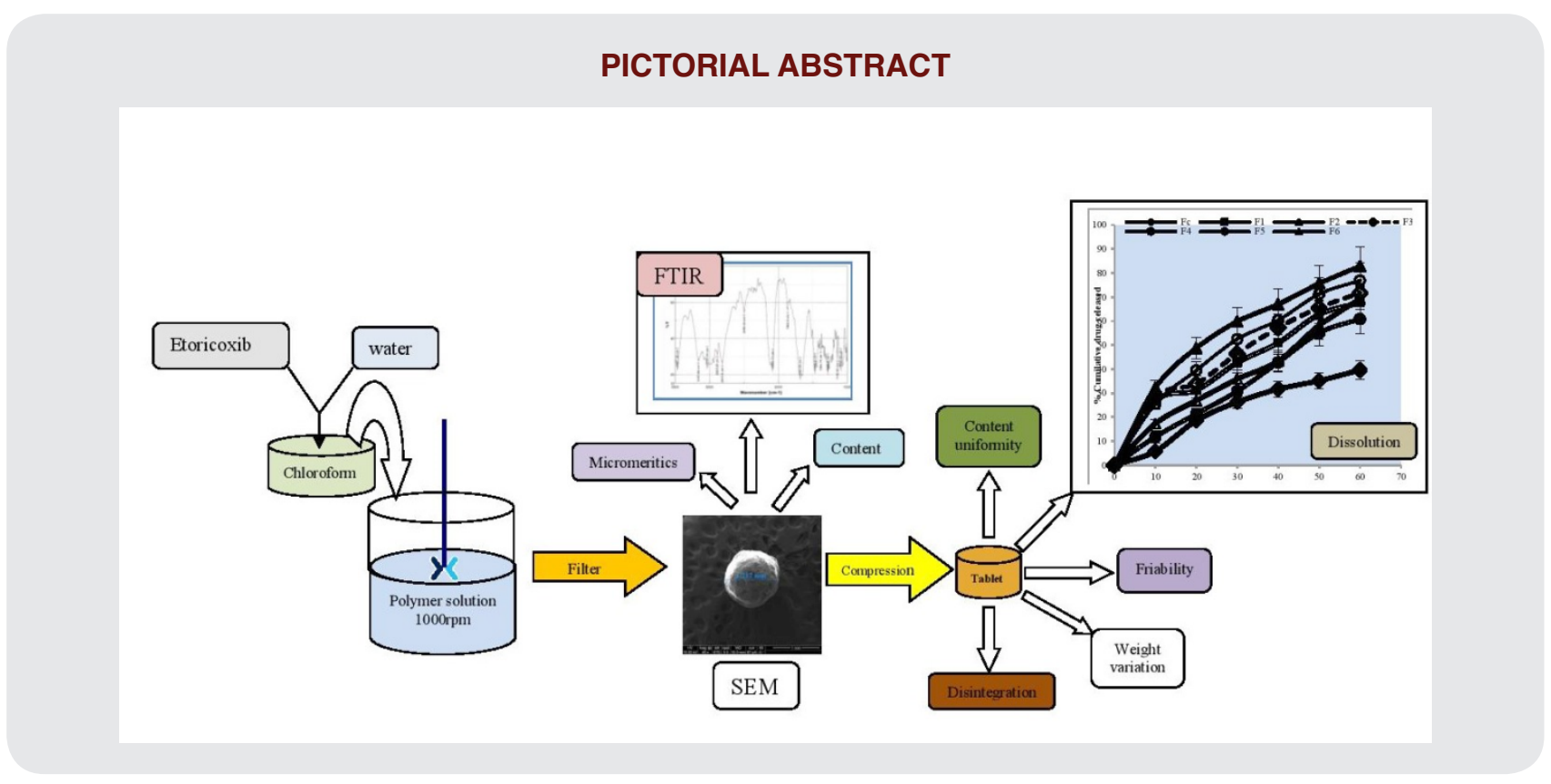




\section{SUMMARY}

Spherical agglomerates of Etoricoxib were successfully prepared using ethanol as a good solvent, chloroform as a bridging solvent and water as a bad solvent for etoricoxib using different polymers like PVP K30 and PEG 6000. FTIR suggested the chemical integrity of the drug in the formulations. SEM studies indicated the agglomerates were discrete and spherical. Further, agglomerates containing polymers were thus found to display good micrometric properties, with improved solubility profile. Values of Carr's index and Hausner's ratio indicated that incorporation of polymers drastically helped in improving the micrometric properties. Spherical agglomerates compressed into tablets using talc and magnesium stearate exhibited better dissolution rate compared to the conventional tablets of etoricoxib. Thus, from the present study it can be concluded that Spherical Agglomeration technique can be an efficient tool to produce directly compressible, cost effective tablets of poorly compressible drugs like etoricoxib.

\section{About Authors}

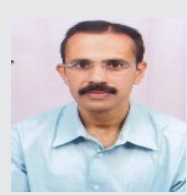

HN Shivakumar is Vice-Principal, Professor and Head of Department of Pharmaceutics at KLE College of Pharmacy, Bengaluru

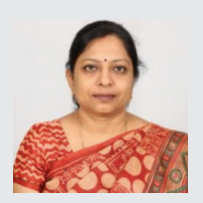

Vanita Somasekhar is a Professor at KLE College of Pharmacy, Bengaluru

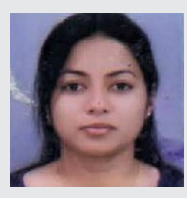

Anwesha Roy completed her M.Pharm in Pharmaceutics from KLE University's College of Pharmacy, Bengaluru

Cite this article: Shivakumar HN, Somasekhar V, Roy A. Preparation and Characterization of Directly Compressible Spherical Agglomerates of Etoricoxib. Indian J of Pharmaceutical Education and Research. 2020;54(4):983-90. 